\title{
Water Vapor Diffusion and Adsorption of Sandstones: Influence of Rock Texture and Composition
}

\author{
Martin Keppert, Jaromír Žumár, Monika Čáchová, Dana Koňáková, Petr Svora, \\ Zbyšek Pavlík, Eva Vejmelková, and Robert Černý
}

\begin{abstract}
Department of Materials Engineering and Chemistry, Faculty of Civil Engineering, Czech Technical University in Prague, Thákurova 7, 16629 Prague 6, Czech Republic
\end{abstract}

Correspondence should be addressed to Martin Keppert; martin.keppert@fsv.cvut.cz

Received 22 April 2016; Accepted 12 June 2016

Academic Editor: Osman Gencel

Copyright (c) 2016 Martin Keppert et al. This is an open access article distributed under the Creative Commons Attribution License, which permits unrestricted use, distribution, and reproduction in any medium, provided the original work is properly cited.

\begin{abstract}
The term sandstone is used for wide range of rocks containing quartz clasts which can be cemented by secondary precipitated quartz or calcite; moreover the space between clasts can be filled by matrix. These facts result in existence of numerous rocks having highly various properties. Sandstones have been used as construction materials due to their good accessibility and workability. Since most of sandstones are porous, water vapor can penetrate through sandstone constructions. The rate of water vapor diffusion, as well as the vapor sorption isotherm, was determined for range of sandstone types. The diffusion resistance factor was found to be dependent on the total porosity of sandstone but the sorption behavior was strongly influenced by nature of the particular sandstone; the specific surface area of stone and presence of clay matrix are determining its sorption isotherm. The published data enable estimating (i) diffusion resistance factor of a sandstone via knowledge of its total porosity and (ii) the sorption isotherm via knowledge of the stone's nature and specific surface area. This approach can significantly reduce the time necessary to acquire vapor-related properties of a sandstone.
\end{abstract}

\section{Introduction}

Ability of a building material to transport and store water vapor is influencing durability and performance of a building structure. Water vapor is one of sources of moisture content in materials and structures; it is entering the structure from the surrounding air of certain relative humidity, and then it is transported by diffusion through the pore system of the material and adsorbed on the surface of material. The water vapor-related material's parameters are significantly influencing indoor climate, performance of building envelopes, or drying of moist structures [1-4]. These parameters are also crucial for modeling of coupled heat and moisture transport in constructions [5-7] which is nowadays necessary tool in design of new constructions as well as in rehabilitation of older structures for new purposes or for improvement of their performance. Sandstones have been used as construction material for centuries; today their importance lies mainly in decorative applications, for example, cladding. Regardless, sandstone is used as load bearing or decorative material and its ability to transport and store water vapor is crucial for the construction durability and performance.

The rate of transport of water vapor in a porous body is usually quantified by means of water vapor diffusion coefficient $D\left(\mathrm{~m}^{2} \mathrm{~s}^{-1}\right)$ which is defined by (1), where $j$ $\left(\mathrm{kg} \mathrm{m}^{-2} \mathrm{~s}^{-1}\right)$ is flux of water vapor and $\rho_{v}\left(\mathrm{~kg} \mathrm{~m}^{-3}\right)$ partial density of water vapor per unit volume of porous body. Water vapor diffusion resistance factor $\mu$ (see (2)) is frequently used in building practice; $D_{a}$ is diffusion coefficient of water vapor in air. It describes the water vapor diffusion resistance of the material in comparison to air at normal pressure:

$$
\begin{aligned}
& j=-D \operatorname{grad} \rho_{v}, \\
& \mu=\frac{D_{a}}{D} .
\end{aligned}
$$

The rate of water vapor diffusion through a material is conventionally measured by a standard (dry/wet) cup method, for example, [8,9], where specimen of a known dimensions is separating two environments of different values of relative 
humidity $(\mathrm{RH})$ and amount of diffused water vapor is measured gravimetrically in time. The diffusion coefficient $D$ is then calculated according to (3), where $\Delta m$ is mass of transported water in time $\tau, d$ and $S$ are dimensions of specimen, $T$ is temperature, $R$ is gas constant, $M$ is molar mass of water, and $\Delta p$ is difference of water partial pressure between the two environments. Fast transient method for $D$ determination was developed in order to reduce the experimental duration [10]. Values of water vapor diffusion resistance factors of various sandstones were published elsewhere [11-13]:

$$
D=\frac{\Delta m \cdot d \cdot R \cdot T}{\tau \cdot S \cdot \Delta p \cdot M}
$$

The ability of a material to store water vapor is described by sorption isotherm, dependence of equilibrium amount of adsorbed moisture upon relative pressure of water vapor in surrounding air. There are several experimental methods of sorption isotherm determination $[14,15]$ but most frequently the specimen is subjected to air of a given constant value of relative humidity and let to reach equilibrium moisture content which is determined gravimetrically. The shape of a sorption isotherm is influenced by mechanism of adsorption prevailing on the given surface; sorption isotherms are conventionally classified according to IUPAC recommendation [16] which has been subject of several proposed modifications $[17,18]$. The experimental sorption data can be fitted with a model, equation describing the sorption isotherm. This approach provides useful information about mechanism of sorption in the studied sorbate-sorbent system and enables generalizing the experimental results on similar systems. Numerous semiempirical and theoretical sorption models were proposed in recent years [19]; applicability of selected models on building materials was tested as well [20]. The Generalized D'Arcy and Watt (GDW) model [19, 21] was used to fit the experimental data in this work. This model assumes that surface of a sorbent contains certain amount of primarily sorption centers where Langmuir monolayer sorption is taking place. The water molecules sorbed at these primary sorption centers act as secondary sorption centers where further water sorption takes place due to cluster formation (Dubinin-Sierpinski theory). The GDW model [21] is expressed by (4), where $M$ is the sorbed amount of water vapor and $\varphi$ is the relative pressure of water vapor. The model involves four parameters: $m$ is the maximum sorbed amount on primary centers; $K$ and $k$ are kinetic constants of sorption on primary and secondary sorption sites; and $w$ is ratio of molecules sorbed on primary centers and converted to secondary centers:

$$
M=\frac{m \cdot K \cdot \varphi}{1+K \cdot \varphi} \cdot \frac{1-k(1-w) \cdot \varphi}{1-k \cdot \varphi} .
$$

The importance of study of water vapor sorption isotherm of building materials, besides the problems mentioned above, lies also in the field of materials durability and, when one is talking specifically about rocks, the water vapor sorption is influencing also deterioration of sculptures and natural monuments $[12,13,22]$. The moisture sorption can be significantly influenced also by present salts what is frequent case in buildings and natural monuments [23].

Water vapor diffusion and sorption properties of sandstones were so far measured and published with respect to behavior of individual rocks; the intention of the present paper is to relate these parameters to fundamental properties and composition of sandstones.

\section{Methods}

The phase composition of stones was studied by X-ray diffraction analysis (diffractometer PANalytical X'PertPRO MPD with $\mathrm{Cu}_{\mathrm{K} \alpha}$ radiation source); the quantification was performed by Rietveld analysis. The SEM images were acquired by help of SEM JEOL JSM-6510; observed particles were characterized by help of EDS detector SDD x-act $10 \mathrm{~mm}^{2}$ INCA. The compressive strength of rocks was evaluated by means of $100 \mathrm{~mm}$ cubes; the bending strength was measured by help of $100 \times 100 \times 300 \mathrm{~mm}$ prisms. Pore size distribution and specific surface area were measured by mercury intrusion porosimetry device Pascal $140+440$ (Thermo). Water vapor sorption was measured gravimetrically by help of device DVS Advantage (Surface Measurement Systems). The water vapor diffusion coefficient and diffusion resistance factor was determined in isothermal conditions $\left(20^{\circ} \mathrm{C}\right)$ according standard [8]; the dry cup arrangement was used in order to avoid overestimation of vapor diffusion coefficient due to simultaneous partial transport of liquid water.

\section{Results}

3.1. Properties of Materials. Six types of sandstones quarried in Czech Republic were selected with respect to various porosity, composition, and diagenesis processes. Stones were sorted and signed according to the increasing porosity (Table 1). Sandstone S 1 (quarry Tešín-Řeka) contains mainly quartz clasts accompanied by smaller amount of feldspar (microcline, albite) and muscovite. Its matrix is formed by calcite and chlorite; muscovite and feldspars are present both as clasts and in matrix (Figure 1). Weak silicification is contributing to very high strength of this stone as well (Table 2). Stone S 2 (Úpice) contains silicified quartz clasts; it contains high amount of matrix composing of kaolinite (23 wt.\% of the whole stone) and muscovite. In contrary stone S 3 (Kocbeře) contains quartz clasts and just limited amount (ca 1\%) of kaolinite. The clasts are highly silicified and the silicification is responsible for very high strength of this stone even though its porosity is ca $15 \%$. Sandstone S 4 (Záměl) is very complicated stone where quartz clasts are accompanied with glauconite, chlorite, and kaolinite. These minerals are present as clasts as well as in the stone matrix. Stone S 5 (Hořice) is similar to $S 2$ but with lower content of kaolinite matrix (14\%) and higher porosity. The highest porosity was exhibited by stone S 6 (Mšené) with just very small amount of kaolinite matrix (ca 1\%) and weak silicification.

The composition and diagenesis of studied stones obviously determine their fundamental physical properties (Table 2). The compressive and bending strength of porous stones are generally inversely dependent on porosity [24, 25]; 
TABLE 1: Composition and porosity of studied sandstones.

\begin{tabular}{|c|c|c|c|c|c|c|}
\hline & & \multicolumn{2}{|c|}{ Clasts } & \multicolumn{2}{|c|}{ Matrix and cement } & \multirow{2}{*}{ Porosity (\%) } \\
\hline & & Nature & Content (\%) & Nature & Content (\%) & \\
\hline \multirow[t]{5}{*}{ S 1} & Tesin & Quartz & 65 & Calcite & 7 & 7.2 \\
\hline & & Muscovite & & Muscovite & Total 10 & \\
\hline & & Feldspars & & Feldspars & Total 10 & \\
\hline & & & & Chlorite & 5 & \\
\hline & & & & weak silicification & & \\
\hline \multirow[t]{3}{*}{ S 2} & Upice & Quartz & 71 & Kaolinite & 23 & 10.4 \\
\hline & & & & Muscovite & 5 & \\
\hline & & & & silicification & & \\
\hline \multirow[t]{2}{*}{ S 3} & Kocbere & Quartz & 99 & Kaolinite & 1 & 14.8 \\
\hline & & & & intensive silicification & & \\
\hline \multirow[t]{4}{*}{ S 4} & Zamel & Quartz & 86 & Chlorite & & 19.5 \\
\hline & & Microcline & & Glauconite & & \\
\hline & & Glauconite & & Kaolinite & & \\
\hline & & & & weak silicification & & \\
\hline \multirow[t]{3}{*}{ S 5} & Horice & Quartz & 84 & Kaolinite & 14 & 27.3 \\
\hline & & & & Illite & 2 & \\
\hline & & & & variable silicification & & \\
\hline \multirow[t]{2}{*}{ S 6} & Msene & Quartz & 99 & Kaolinite & 1 & 28.2 \\
\hline & & & & weak silicification & & \\
\hline
\end{tabular}

the studied sandstones obey this rule with one exception: stone S 4 has unexpectedly high strength due to intensive silicification. The composition of sandstones is reflected also in their pore size distribution (Figure 2). Pore system of the stone $\mathrm{S} 6$ is formed mainly by large pores, voids between quartz grains (mean pore diameter $37 \mu \mathrm{m}$, Table 2). The porosity of stone S 5 is nearly the same but an important difference lies in its pore size distribution; S 5 contains relatively high amount of clays and thus its pore system is bimodal; it is formed by capillaries and in addition also by smaller pores $(0.1-1 \mu \mathrm{m})$ in clay matrix. Sandstone S 4 is similar to $S 5$ but the total porosity is smaller due to lower volume of capillary pores. S 3 is sort of analogy of S 6; there is very small amount of kaolinite and thus the pore size distribution is unimodal, and pore system contains nearly uniquely capillaries between 10 and $100 \mu \mathrm{m}$. The mean pore diameters of S 3 and S 6 are roughly equal. Stones S 1 and S 2 do not contain the large interparticular capillaries but their pore system is composed just from pores in their matrices. Consequently their values of mean pore diameter are of one and two orders of magnitude lower. Specific surface area (SSA) of stones is an important parameter with respect to their ability to adsorb water vapor. The highest values were obtained in case of stones S 4 and S 1 due to presence of high amount of small pores in their matrices; smaller pores obviously contribute to specific surface area more than large pores of the same specific volume. It is obvious that "sandstone" cannot be regarded as a single material but one has to consider its original character and composition when properties of a sandstone are discussed.
3.2. Diffusion of Water Vapor in Sandstones. The dependence of vapor diffusion coefficient (measured by dry cup) of studied sandstones on their porosity $P(\%)$ is shown in Figure 3. The diffusion coefficient $D\left(\mathrm{~m}^{2} \mathrm{~s}^{-1}\right)$ is increasing linearly upon porosity. When the same results are expressed in form of water vapor diffusion resistance factor $\mu$, one obtains inversely proportional function (Figure 4 ). The corresponding equations are as follows:

$$
\begin{aligned}
& D=6.37 \cdot 10^{-5} \cdot P-1.72 \cdot 10^{-7}, \\
& \mu=\frac{2.3 \cdot 10^{-5}}{6.37 \cdot 10^{-5} \cdot P-1.72 \cdot 10^{-7}} .
\end{aligned}
$$

3.3. Sorption of Water Vapor on Sandstones. Primary water vapor sorption isotherms where mass of adsorbed water is related to mass of sorbent (stone) are shown in Figure 5. Hysteresis between adsorption and desorption isotherms indicates occurrence of condensation of water vapor in pores. The present data feature wide range of adsorbed vapor amounts on a "single" type of rock (i.e., sandstone). The highest sorption was measured in case of sample S 4 while the lowest in S 6 . These two materials are also the extremes (among of the studied stones) regarding the specific surface area; S 4 achieved the highest value of SSA while S 6 the lowest. The sorption values of S 3 were found to be similar to $S 6$. 


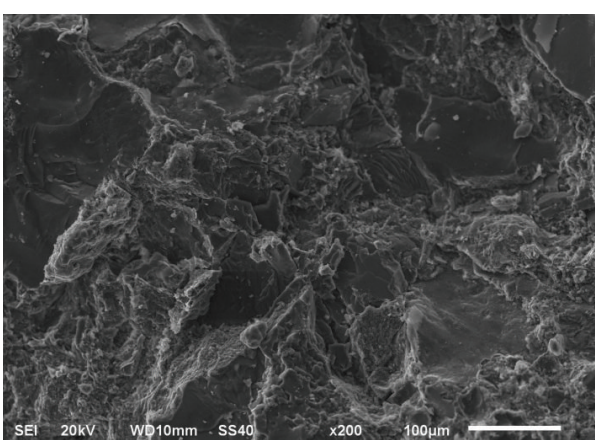

(a)

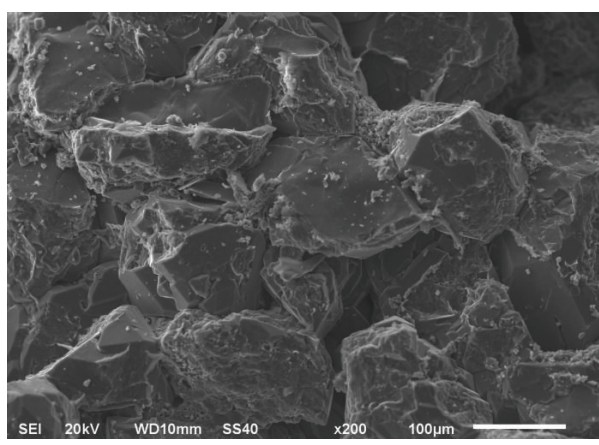

(c)

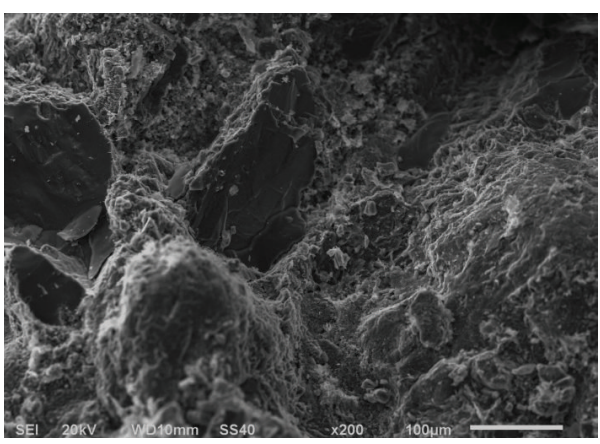

(e)

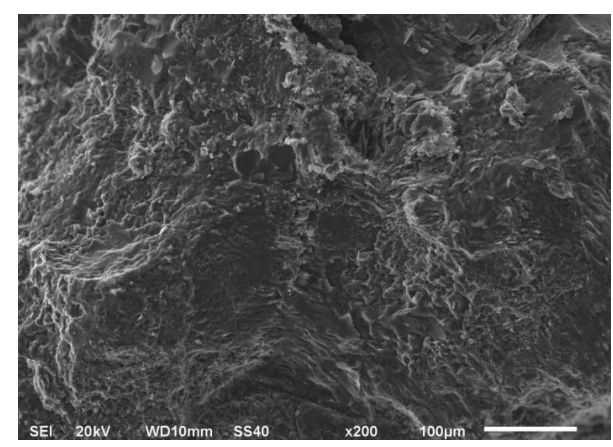

(b)

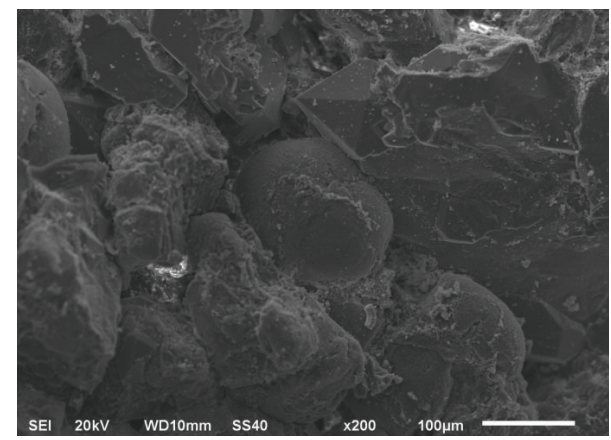

(d)

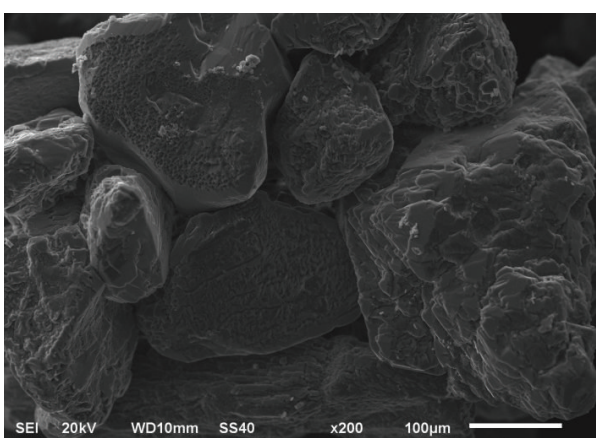

(f)

Figure 1: SEM of studied sandstones ((a) S 1, (f) S 6).

TABLE 2: Fundamental properties of studied sandstones.

\begin{tabular}{lcccccc}
\hline & $\begin{array}{c}\text { Porosity } \\
\%\end{array}$ & $\begin{array}{c}\text { Specific pore volume } \\
\mathrm{cm}^{3} \mathrm{~g}^{-1}\end{array}$ & $\begin{array}{c}\text { Mean pore diameter } \\
\text { Micrometer }\end{array}$ & $\begin{array}{c}\text { Specific surface area } \\
\mathrm{m}^{2} \mathrm{~g}^{-1}\end{array}$ & $\begin{array}{c}\text { Compressive strength } \\
\mathrm{MPa}\end{array}$ & $\begin{array}{c}\text { Bending strength } \\
\mathrm{MPa}\end{array}$ \\
\hline S 1 & 7.2 & 0.027 & 0.11 & 2.014 & 82.8 & 14.2 \\
S 2 & 10.4 & 0.040 & 1.53 & 0.679 & 63.5 & 7.6 \\
S 3 & 14.8 & 0.061 & 32.73 & 0.67 & 85.4 & 25.6 \\
S 4 & 19.5 & 0.088 & 18.60 & 3.303 & 21.1 & 5.1 \\
S 5 & 27.3 & 0.133 & 38.37 & 0.754 & 8.7 & 3.8 \\
S 6 & 28.2 & 0.139 & 36.51 & 0.44 & 1.6 & \\
\hline
\end{tabular}

\section{Discussion}

The experimentally determined water vapor diffusion resistance factors, when being plotted upon total porosity (Figure 4), are in very good agreement with data published in studies [11-13]. The total porosity can be regarded as the crucial factor controlling the rate of vapor diffusion in sandstones; influence of any other parameter was not observed. The explanation of identified different sorption behavior of individual sandstones has to be searched in different composition and pore size distribution of the stones; clearly these two factors are associated. Since the water vapor 


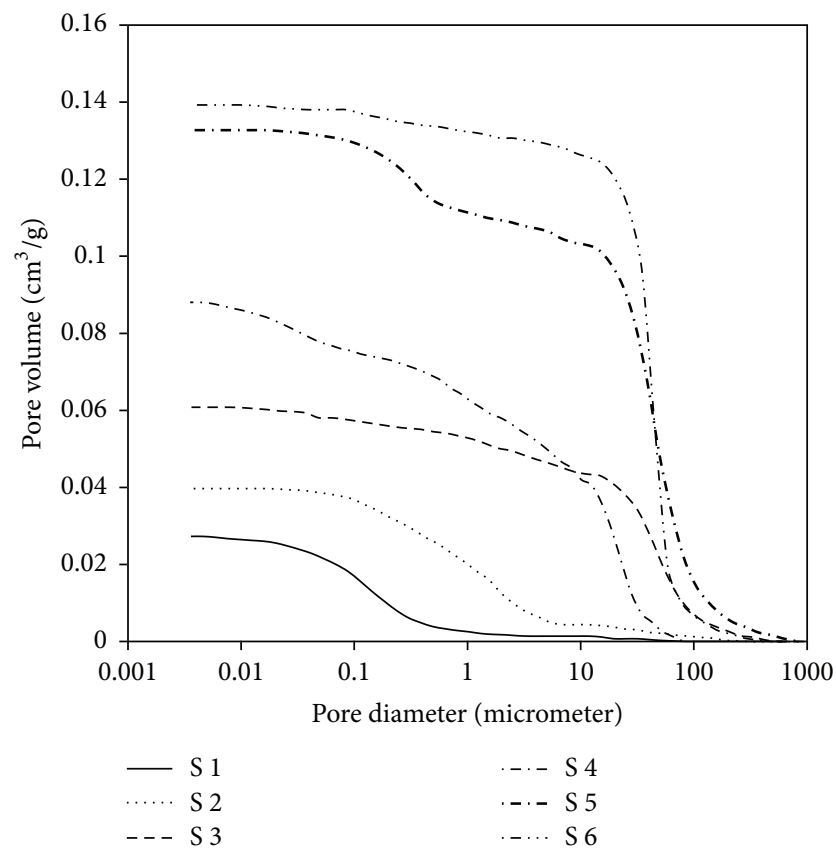

FIGURE 2: Pore size distribution.

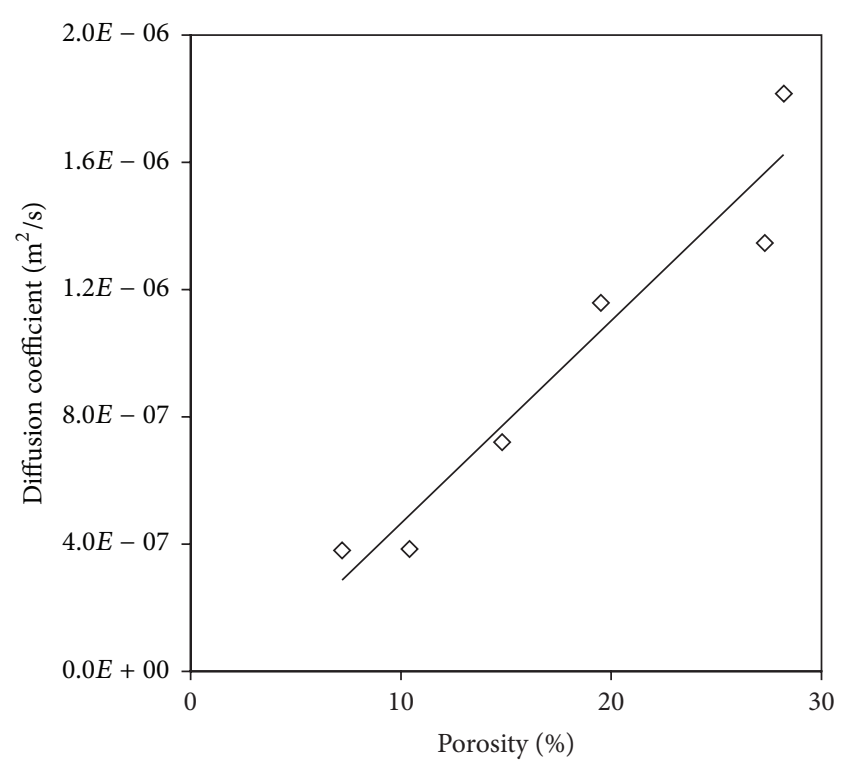

FIGURE 3: Dependence of water vapor diffusion coefficients of sandstones on porosity.

adsorption is a surface process the experimental sorption data were replotted as mass of adsorbed vapor-related to unit of surface area of a given stone (Figure 6). There, the range of acquired values is somewhat smaller; the experimental data of S 1, S 2, S 4, and S 5 relatively well collapse to a similar values. The remaining stones (S 3 and $S 6$ ) reached somewhat lower sorption per $\mathrm{m}^{2}$ of surface. The difference between these two groups of sandstones lies in their nature; stones $S 3$ and $S 6$ contain just negligible amount of matrix while quartz clasts (and quartz cement) are their dominant components; the other stones contain significant amount of matrix. One

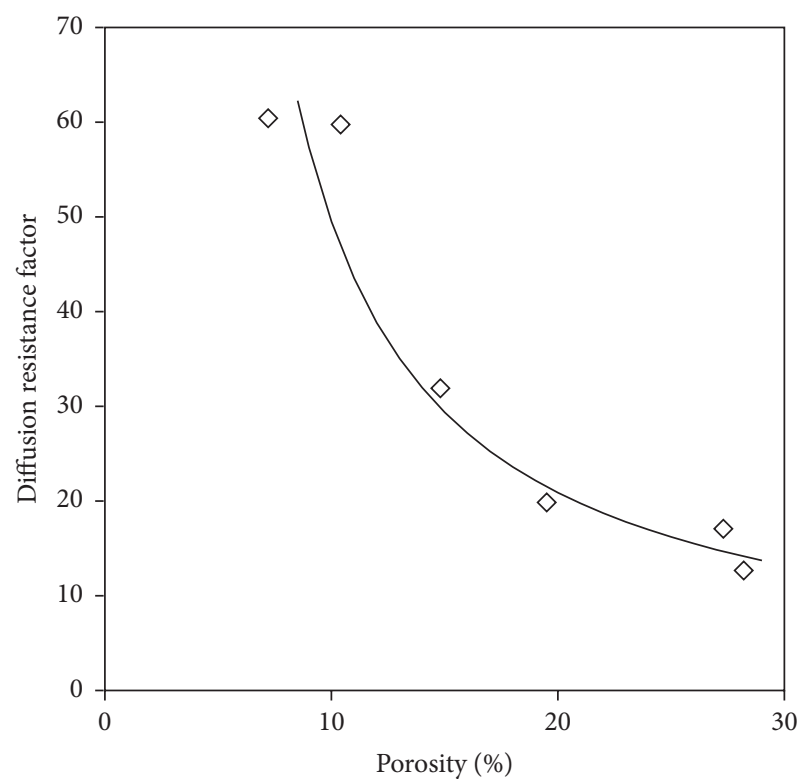

Figure 4: Diffusion resistance factor of sandstones as function of porosity.

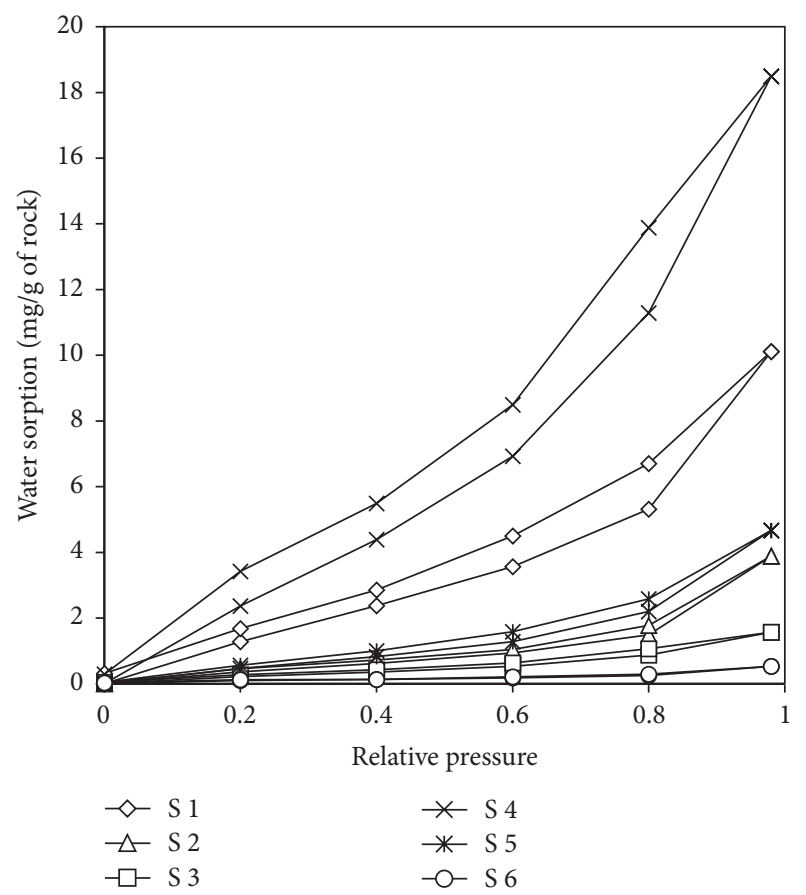

FIGURE 5: Sorption/desorption isotherms of sandstones expressed by $\mathrm{mg}$ of water adsorbed per $1 \mathrm{~g}$ of sample.

observes that presence of matrix in stones clearly increases SSA and also ability of water vapor sorption. Nevertheless this link is not straightforward; in such case all isotherms in Figure 4 would collapse together. In fact nature of surface is important as well; samples S 2 and S 3 have similar specific surface area but adsorbed amount is higher in $S 2$ where high amount of kaolinite is present. The adsorbed maximum amount of water on quartz or calcite is about $1 \mathrm{mg} / \mathrm{g}$ [26], 


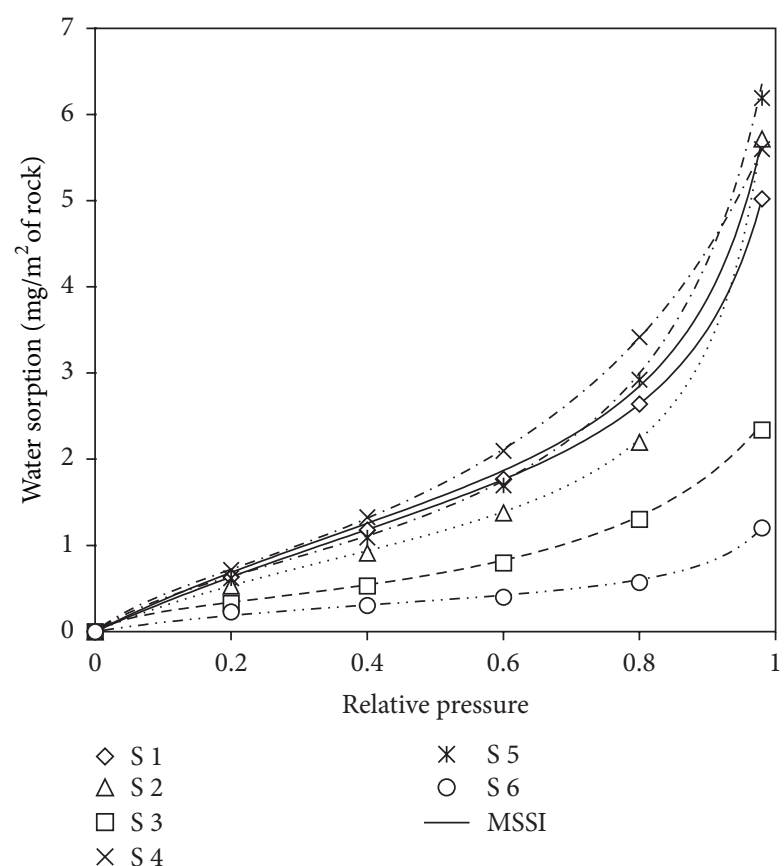

FIGURE 6: Sorption isotherms where mass of adsorbed water is expressed per unit specific surface area ( $\mathrm{m}^{2}$ of rock). Points: experimental data; lines: fitted GDW isotherms.

TABLE 3: Coefficients of GDW sorption isotherms (see (4)) of studied stones.

\begin{tabular}{lcccc}
\hline & $m$ & $K$ & $k$ & $w$ \\
\hline S 1 & 4.004 & 0.8864 & 0.8984 & 0.23 \\
S 2 & 1.802 & 1.8803 & 0.9365 & 0.36 \\
S 3 & 0.480 & 7.3457 & 0.8547 & 0.93 \\
S 4 & 4.723 & 0.9514 & 0.9264 & 0.25 \\
S 5 & 4.608 & 0.7285 & 0.8597 & 0.35 \\
S 6 & 0.441 & 2.1500 & 0.8200 & 0.75 \\
MSSI & 3.336 & 1.2185 & 0.9028 & 0.29 \\
\hline
\end{tabular}

similarly to values obtained for S 3 and S 6 samples (Figure 5) where quartz is nearly the sole component. On the other hand, clay minerals, which are present in other samples, are generally able to adsorb tens to hundreds of $\mathrm{mg}$ of water per $\mathrm{g}[27,28]$.

In order to find a general relationship between adsorbed water amount and properties of stones, the experimental sorption data (expressed per unit specific surface area) were fitted by GDW isotherm (see (4)); the regression coefficients are provided in Table 3 (adsorbed amount in $\mathrm{mg} / \mathrm{m}^{2}$, dimensionless relative pressure). Since the experimental data for samples S 1, S 2, S 4, and S 5 are close to each other and these four stones contain significant amount of (mostly) clayey matrix, an overall fitting for these four samples was performed as well; the obtained isotherm MSSI (matrix sandstone sorption isotherm) is shown in Figure 4. The values of $m$ parameter (adsorbed amount on primary centers) are lower for "quartz-only sandstones" S 3 and S 6 compared to the "matrix-containing" materials. The value of parameter $w$, expressing the amount of secondary adsorption centers, is significantly higher in case of S 3 and S 6 which correspond to lower adsorbed amount on primary centers on quartz compared to clay minerals and thus the effort on adsorption on secondary sites is higher.

\section{Conclusions}

The water vapor diffusion and storage parameters of six different sandstones were determined. While the diffusion resistance factor was found to be simply dependent on the total porosity (studied range 7-28\%) the adsorption behavior was more complicated. The sorption isotherms acquired on studied sandstones were influenced by (i) specific surface area of the stone and (ii) its composition, specifically by content of clay minerals. When the adsorbed amount is related to $\mathrm{m}^{2}$ of stone, the data acquired on sandstones with clay matrix collapsed to a single line while adsorbed amounts on "quartzonly" sandstones are lower. The regression coefficients of GDW sorption isotherm indicate different mechanism as well; the stones without matrix contain higher amount of secondary sorption centers than stones with matrix where Langmuir sorption is prevailing. The acquired data enable estimating (i) diffusion resistance factor of a sandstone via knowledge of its total porosity and (ii) the sorption isotherm via knowledge of the stone's nature and specific surface area.

\section{Competing Interests}

The authors declare that there are no competing interests regarding the publication of this paper.

\section{Acknowledgments}

This research has been supported by the Czech Science Foundation under Project no. 14-17207S "Transport Parameters and Durability of Porous Rocks."

\section{References}

[1] A. H. Holm and H. M. Kuenzel, "Practical application of an uncertainty approach for hygrothermal building simulationsdrying of an AAC flat roof," Building and Environment, vol. 37, no. 8-9, pp. 883-889, 2002.

[2] V. Kočí, J. Maděra, and R. Černý, "Exterior thermal insulation systems for AAC building envelopes: computational analysis aimed at increasing service life," Energy and Buildings, vol. 47, pp. 84-90, 2012.

[3] Z. Pavlík and R. Černý, "Hygrothermal performance study of an innovative interior thermal insulation system," Applied Thermal Engineering, vol. 29, no. 10, pp. 1941-1946, 2009.

[4] V. Kočí, J. Maděra, and R. Černý, "Computer aided design of interior thermal insulation system suitable for autoclaved aerated concrete structures," Applied Thermal Engineering, vol. 58, no. 1-2, pp. 165-172, 2013.

[5] M. Qin, R. Belarbi, A. Aït-Mokhtar, and L.-O. Nilsson, "Coupled heat and moisture transfer in multi-layer building materials," Construction and Building Materials, vol. 23, no. 2, pp. 967975, 2009. 
[6] H. L. S. C. Hens, "Combined heat, air, moisture modelling: a look back, how, of help?" Building and Environment, vol. 91, pp. 138-151, 2015.

[7] J. Carmeliet and S. Roels, "Determination of the isothermal moisture transport properties of porous building materials," Journal of Thermal Envelope and Building Science, vol. 24, no. 3, pp. 183-210, 2001.

[8] ISO, "Hygrothermal performance of building materials and products," Tech. Rep. EN ISO 12572, Determination of Water Vapour Transmission Properties, 2001.

[9] ASTM E96-95, Standard test methods for water vapor transmission of materials, 2001.

[10] Z. Pavlík, J. Žumár, M. Pavlíková, and R. Černý, "A Boltzmann transformation method for investigation of water vapor transport in building materials," Journal of Building Physics, vol. 35, no. 3, pp. 213-223, 2012.

[11] J. Ruedrich, T. Bartelsen, R. Dohrmann, and S. Siegesmund, "Moisture expansion as a deterioration factor for sandstone used in buildings," Environmental Earth Sciences, vol. 63, no. 7, pp. 1545-1564, 2011.

[12] H. Stück, S. Siegesmund, and J. Rüdrich, "Weathering behaviour and construction suitability of dimension stones from the Drei Gleichen area (Thuringia, Germany)," Environmental Earth Sciences, vol. 63, no. 7, pp. 1763-1786, 2011.

[13] H. Stück, R. Plagge, and S. Siegesmund, "Numerical modeling of moisture transport in sandstone: the influence of pore space, fabric and clay content," Environmental Earth Sciences, vol. 69, no. 4, pp. 1161-1187, 2013.

[14] B. Johannesson and M. Janz, "Test of four different experimental methods to determine sorption isotherms," Journal of Materials in Civil Engineering, vol. 14, no. 6, pp. 471-477, 2002.

[15] C. Franzen and P. W. Mirwald, "Moisture content of natural stone: static and dynamic equilibrium with atmospheric humidity," Environmental Geology, vol. 46, no. 3-4, pp. 391-401, 2004.

[16] IUPAC, "Reporting physisorption data for gas/solid systems with special reference to the determination of surface area and porosity," Pure \& Applied Chemistry, vol. 57, pp. 603-619, 1985.

[17] M. D. Donohue and G. L. Aranovich, "Classification of Gibbs adsorption isotherms," Advances in Colloid and Interface Science, vol. 76-77, pp. 137-152, 1998.

[18] J. Blahovec and S. Yanniotis, "Modified classification of sorption isotherms," Journal of Food Engineering, vol. 91, no. 1, pp. 72-77, 2009.

[19] S. Furmaniak, P. A. Gauden, A. P. Terzyk, and G. Rychlicki, "Water adsorption on carbons-critical review of the most popular analytical approaches," Advances in Colloid and Interface Science, vol. 137, no. 2, pp. 82-143, 2008.

[20] Z. Pavlík, J. Žumár, I. Medved, and R. Černý, "Water vapor adsorption in porous building materials: experimental measurement and theoretical analysis," Transport in Porous Media, vol. 91, no. 3, pp. 939-954, 2012.

[21] S. Furmaniak, A. P. Terzyk, R. Gołembiewski, P. A. Gauden, and L. Czepirski, "Searching the most optimal model of water sorption on foodstuffs in the whole range of relative humidity," Food Research International, vol. 42, no. 8, pp. 1203-1214, 2009.

[22] Z. Pavlík, P. Michálek, M. Pavlíková, I. Kopecká, I. Maxová, and R. Černý, "Water and salt transport and storage properties of Mšené sandstone," Construction and Building Materials, vol. 22, no. 8, pp. 1736-1748, 2008.

[23] C. Franzen and P. W. Mirwald, "Moisture sorption behaviour of salt mixtures in porous stone," Chemie der Erde, vol. 69, no. 1, pp. 91-98, 2009.
[24] C. Chang, M. D. Zoback, and A. Khaksar, "Empirical relations between rock strength and physical properties in sedimentary rocks," Journal of Petroleum Science and Engineering, vol. 51, no. 3-4, pp. 223-237, 2006.

[25] N. K. Tamrakar, S. Yokota, and S. D. Shrestha, "Relationships among mechanical, physical and petrographic properties of Siwalik sandstones, Central Nepal Sub-Himalayas," Engineering Geology, vol. 90, no. 3-4, pp. 105-123, 2007.

[26] N. Hackerman and A. C. Hall, "The adsorption of water vapor on quartz and calcite," The Journal of Physical Chemistry, vol. 62, no. 10, pp. 1212-1214, 1958.

[27] M. S. Gruszkiewicz, J. Horita, J. M. Simonson, R. E. Mesmer, and J. B. Hulen, "Water adsorption at high temperature on core samples from The Geysers geothermal field, California, USA," Geothermics, vol. 30, no. 2-3, pp. 269-302, 2001.

[28] P. Mokrejs, A. Zikanova, D. Hradil et al., "The influence of heat pre-treatment on the sorption of water vapour on bentonite," Adsorption, vol. 11, no. 1, pp. 57-63, 2005. 

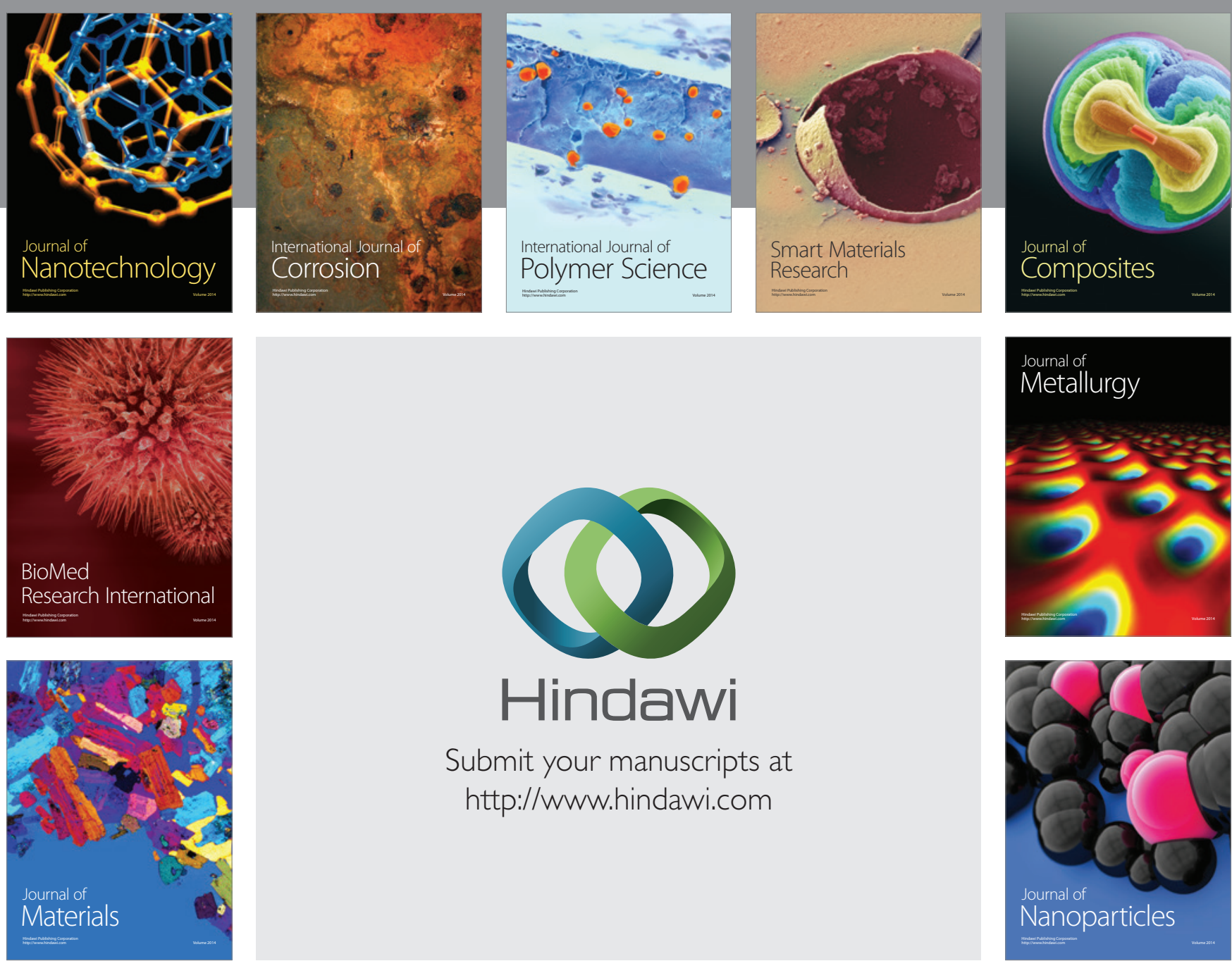

\section{Hindawi}

Submit your manuscripts at

http://www.hindawi.com

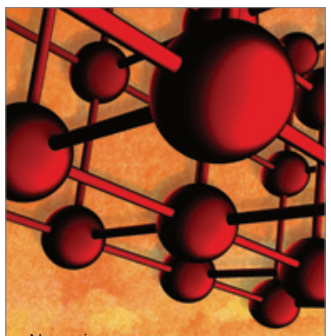

Materials Science and Engineering
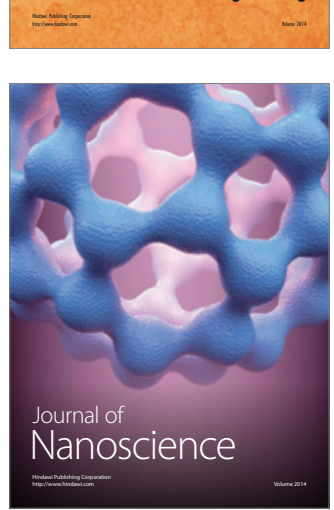
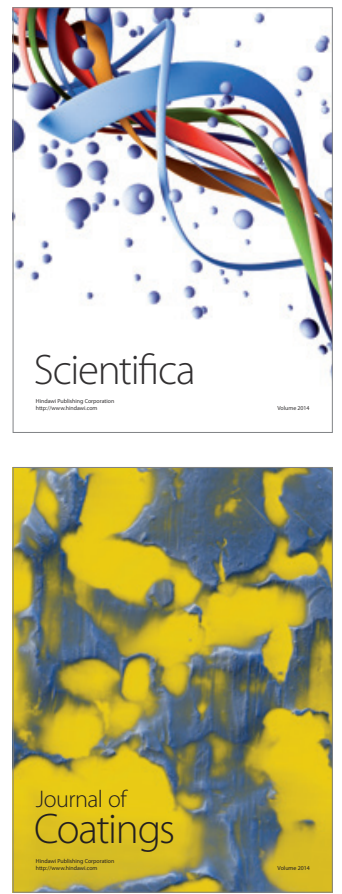
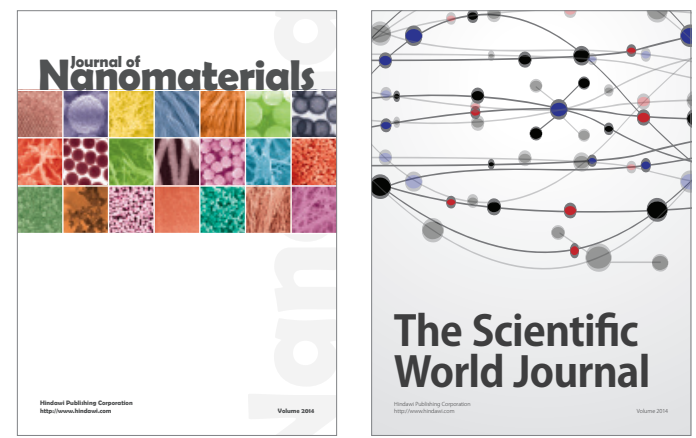

The Scientific World Journal
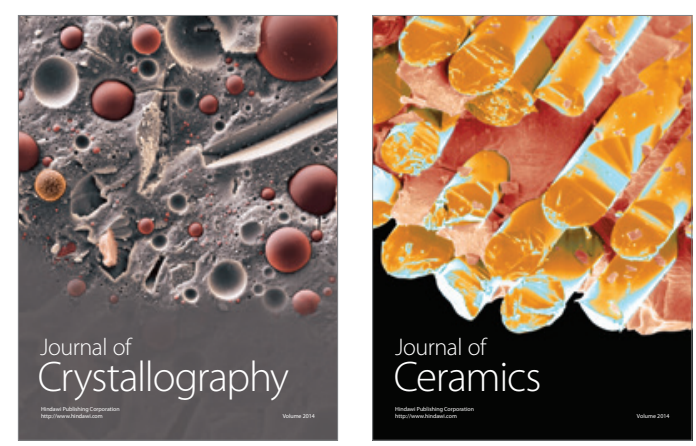
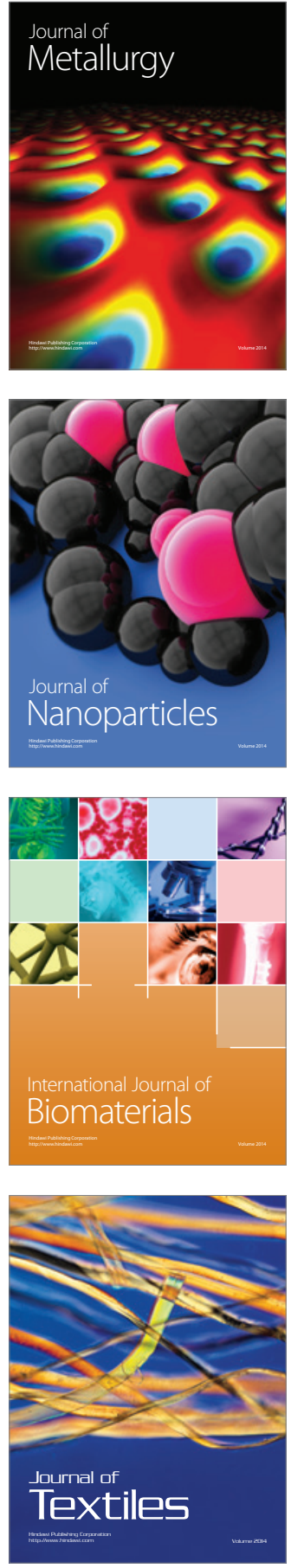